\title{
Entre el periodismo y la literatura: aproximación a los racconti-inchiesta de Leonardo Sciascia
}

\author{
Javier SeRrano PuCHE \\ Universidad de Navarra \\ jserrano@unav.es
}

Recibido: 8/03/2011

Aceptado: 10/10/2011

\begin{abstract}
Resumen
En la trayectoria intelectual del escritor siciliano Leonardo Sciascia (1921-1989) ocupa un lugar importante su dedicación al Periodismo como articulista habitual de diarios italianos y como autor de reportajes novelados. En éstos, Sciascia indagaba en torno un determinado episodio histórico, más o menos reciente pero siempre de algún modo oscuro o de sentido confuso y, con toda la documentación a su alcance y el empleo de técnicas narrativas, construía un relato de investigación para esclarecer los hechos. Este artículo expone las características distintivas del racconto-inchiesta como subgénero del periodismo literario, mostrando la confianza del autor italiano en restablecer la verdad de los acontecimientos a través de una escritura híbrida entre el periodismo y la literatura.

Palabras clave: Periodismo literario, Leonardo Sciascia, periodismo de investigación, escritura no ficción.

\section{On the boundary between Journalism and Literature: an approach to the "racconti-inchiesta" of Leonardo Sciascia}

\begin{abstract}
In the intellectual evolution of the Sicilian writer Leonardo Sciascia (1921-1989) there is an outstanding place for his dedication to journalism as a columnist in Italian newspapers and as an author of fictionalized stories. In these, Sciascia would investigate about a more or less recent historical episode that was still somewhat obscure or with an unclear meaning. Thus, with all the available documentation and using some narrative techniques, he would build up an investigation report with the aim of clarifying the facts. This paper describes the distinguishing features of the racconto-inchiesta as a genre of literary journalism and as a means for the Italian writer to restore the truth of the events through a hybrid writing between Journalism and Literature.
\end{abstract}

Keywords: Leonardo Sciascia, literary journalism, investigative journalism, non-fiction writing.

\section{Referencia normalizada}

SERRANO PUCHE, Javier (2011): "Entre el periodismo y la literatura: aproximación a los racconti-inchiesta de Leonardo Sciascia”. Estudios sobre el mensaje periodístico. Vol. 17, núm. 2, págs.: 661-674. Madrid, Servicio de Publicaciones de la Universidad Complutense.

Sumario: 1. Introducción. 2. El racconto-inchiesta como género periodístico-literario. 3. Panorama de los racconti-inchiesta de Leonardo Sciascia. 4. Conclusiones. 5. Referencias bibliográficas.

\section{Introducción}

En el panorama de la literatura europea de la segunda mitad del siglo XX, el escritor siciliano Leonardo SCIASCIA (1921-1989) ocupa un lugar destacado. Fue autor de una extensa y variada obra, publicada en el contexto de la convulsa realidad política y social de la Italia contemporánea, en la que con frecuencia Sciascia hallaba inspiración para sus novelas policíacas, relatos o ensayos.

Durante casi 35 años, Sciascia también ejerció como columnista en diversos diarios y revistas italianos (SERRANO, 2011). Es ésta una faceta destacada en su trayec- 
toria intelectual y que le confirió una gran proyección pública. Su experiencia como escritor en prensa, que comenzó a la edad de 34 años y mantuvo hasta el final de su vida, se compuso de tres grandes períodos:

1) Los primeros pasos como columnista en la prensa regional, a partir de la colaboración en 1955 en el periódico palermitano L'Ora, donde publicó de manera regular durante toda la década de los sesenta. Son emblemáticas de este período sus columnas bajo la rúbrica Quaderno, entre 1964 y 1968.

2) El salto a la prensa de difusión nacional en 1969, de la mano del Corriere della Sera, donde escribió de manera asidua -con algunos lapsos de tiempo por desavenencias con la dirección del diario, en los que traslada su firma a las páginas de La Stampa- hasta su fallecimiento en 1989.

3) La acentuación durante los años ochenta del carácter polémico de sus opiniones acerca de la política nacional y la lucha antimafia, que suscitaron numerosas controversias en las páginas del Corriere y La Stampa. Paralelamente, la extensión de sus colaboraciones a revistas y semanarios como Epoca, Panorama o L'Espresso.

El desarrollo de esta actividad periodística estuvo muy vinculado al de la producción literaria del autor: tanto en las columnas y artículos como en las obras de ficción afloraban, aunque bajo géneros diferentes, temas e intereses similares. En algunas ocasiones, bosquejaba en la prensa una reflexión que más tarde serviría como germen y punto de partida para una novela; en otras, las páginas del diario eran el espacio en que presentaba sus relatos de investigación antes de su publicación editorial; con frecuencia, en los periódicos se alimentaron y resolvieron las controversias generadas por algunas de sus obras. Empleaba la prensa, por tanto, como tribuna desde la cual manifestar libremente su opinión, a menudo polémica y contraria al poder institucional. Es significativo que no se apoyase para ello también en la televisión, pero desconfiaba seriamente de un medio de comunicación cuya difusión en los hogares había provocado, en su opinión, un fuerte descenso en la práctica de la conversación y de la lectura; y que estaba en el origen del "declive de la inteligencia y del aumento del índice de estupidez de los ciudadanos" (SCIASCIA, 2007: 260-261).

No obstante fue también muy crítico con la creciente falta de profesionalidad que apreciaba en los diarios impresos y que consideraba inaceptable (SCIASCIA, 1999: 809). Pese a todo, ya fuera en unas u otras cabeceras, mantuvo siempre viva esa vertiente de opinión y valoración de la actualidad. Su confianza en el poder de la palabra escrita y su arraigada conciencia cívica explican que concibiera las páginas de los periódicos como un espacio idóneo para desplegar sus apreciaciones e inquietudes culturales, políticas, sociales, artísticas, existenciales.

\section{El racconto-inchiesta como género periodístico-literario}

Como indicábamos antes, en las páginas de los periódicos Sciascia publicó varios relatos de investigación (denominados en italiano racconto-inchiesta-raccontiinchiesta en plural- o, cuando su extensión se aproxima al de una novela y es directamente publicado por una editorial, romanzo-inchiesta). Según confesó el autor siciliano (NIGRO, 2003: 107), consideraba como precursor y modelo del género la Sto- 
ria della colonna infame (Historia de la columna infame, 1842) de Alessandro MANZONI, una narración del proceso judicial que se desarrolló en Milán con ocasión de la peste de $1630 \mathrm{y}$ en el que fueron injustamente condenados a muerte varios hombres, acusados de ser los propagadores de la plaga. El tema ya aparecía en I promessi sposi (Los novios, 1827) y en un principio Manzoni pensó que fuera un apéndice de la novela, aunque finalmente apareció publicada de modo independiente.

De Storia della colonna infame Sciascia aprendió a tomar como punto de partida algún hecho realmente acaecido, sobre el que primero se documentaba (a través de la prensa de la época, de actas judiciales, informes de la policía, diarios y testimonios de los protagonistas...) y que luego reconstruía por medio de la narración y la inclusión en el relato de algunos de dichos documentos. Son sucesos que tuvieron lugar en el pasado más o menos reciente de la Historia italiana y en los que, como señalaremos más adelante, Sciascia indaga no sólo para comprender una determinada etapa histórica, sino con la pretensión de que aquello ilumine también el presente desde el que escribe. Por su enfoque centrado sobre los acontecimientos menores y significativos $\mathrm{y}$, sobre todo, por su dimensión narrativa, este procedimiento lo aproxima en cierto modo a la microhistoria, corriente historiográfica que alcanzó su apogeo simultáneamente a la publicación de los racconti-inchiesta sciascianos y que se desmarcaba de la historiografía convencional, de la que demostró el escritor siciliano una desconfianza creciente (SCIASCIA, 1979: 82). Fue entonces, en la década de 1970, cuando "las nuevas tendencias del narrativismo, el relativismo y la apuesta por la pluridisciplinariedad se fueron concretando, poco a poco, en nuevos gustos temáticos y el desarrollo de nuevas metodologías en el campo de la historiografía" (AURELL, 2005: 183). Fruto de ello es la microhistoria, basada en la narración de un hecho singular con aspiraciones globalizantes, como evidencia, ya desde el título, una de sus obras más emblemáticas: Il formaggio e i vermi: Il cosmo di un mugnaio del '500 (El queso y los gusanos: el cosmos según un molinero del siglo XVI, 1976), de Carlo Ginzburg.

No obstante, más que una hibridación entre la literatura y la historia, los relatos de investigación de Sciascia transitan entre lo literario y lo periodístico. Como señala Albert CHILlón, constituyen una modalidad de reportaje novelado -en tanto que "incorporan algunos recursos compositivos y estilísticos de origen novelesco, pero sin que tal asimilación sea completa" (1999: 193) - y son muestra de un "periodismo de denuncia, basado en la investigación meticulosa y animado en última instancia por un propósito de regeneración democrática de la vida pública" (Ibid.: 326). Desde otro punto de vista, y siguiendo la categorización de María Jesús CASALs (2005: 492), los racconti-inchiesta sciascianos se conformarían, junto con una dimensión literaria en la que ahondaremos más adelante, como la simbiosis entre los reportajes de base histórica - por cuanto que "acercan la memoria del pasado y dan sentido a situaciones del presente" - y los reportajes de investigación, por su "modo de obtención de información riguroso, paciente y difícil, que busca lo que el poder esconde, que es vigilante con los principios democráticos y con los derechos de los ciudadanos" (Ibid.: 493).

Casi todos los racconti-inchiesta escritos por Sciascia narran algún proceso judicial o investigación de la policía. La lectura perspicaz que realiza el escritor de los documentos disponibles sobre cada uno de los casos narrados desvela con frecuencia 
errores y omisiones en la investigación, contradicciones y falta de rigor en el desarrollo de procesos que a menudo concluyen con la condena injusta de personas inocentes o con la absolución de los culpables. Al mismo tiempo, como elemento de interpretación e instrumento que ayude a paliar las lagunas y la escasez de documentos, Sciascia se sirve continuamente de la ficción. Por medio de la inclusión intertextual de fragmentos de otras obras, de la apelación a personajes o motivos literarios, intenta perfilar los rasgos de carácter de las personas que protagonizan el acontecimiento o entender lo que realmente ocurrió y no encuentra verdadera explicación en los textos que hasta entonces daban cuenta del suceso en cuestión.

Como bien ha explicado Stefano TANI (1990: 67), este interés "por los hechos reales y sobre todo por los hechos escondidos y oscuros, por los conflictos y las irregularidades enmascaradas o sofocadas" se manifiesta en una indagación de carácter metanarrativo, posmoderno, porque se convierte en "una exégesis filológica, mezcla de textos diversos y contradictorios, análisis de las fuentes, proceso de un proceso, inquisición de una inquisición" (Ibid.: 69). En definitiva, como afirma VILA-MATAS (2010: 39), "la investigación de Sciascia se dedica a abrir todo tipo de puertas y a inaugurar sospechas y a adentrarse en las brechas de la verdad oficial, creando un tipo de incertidumbre que demuestra cómo desde el género periodístico se puede uno enredar con libertad en el gran misterio del mundo y alcanzar cotas de alta literatura, bien alejadas de ese tipo de información que da tantas explicaciones a todo".

\section{Panorama de los racconti-inchiesta de Leonardo Sciascia}

Leonardo Sciascia publicó su primer racconto-inchiesta en 1971, con el título de Atti relativi alla morte di Raymond Roussel (Actas relativas a la muerte de Raymond Roussel). Su aparición marcó un hito destacado dentro de la obra del autor, que empezaba a tener una mayor proyección pública como articulista habitual del Corriere della Sera y como un escritor de alcance ya no sólo siciliano, sino italiano y europeo. En esta investigación Sciascia analiza las misteriosas circunstancias en que murió el escritor francés Raymond Roussel en un lujoso hotel de Palermo el 14 de julio de 1933. Indaga y expone los documentos policiales que se refieren a los últimas días de Roussel y a su defunción con la actitud de un detective; de tal manera que, como ha puesto de relieve Giuseppe TrAINA (1999: 52), aquellos papeles "casi mudos a una lectura fiduciosa y pasiva, se vuelven parlantes en cuanto son reescritos y asuntos al cielo de la literatura, de la significación". Aparecen así contradicciones y lagunas en las pesquisas que rápidamente cerró la policía fascista, aunque a la postre tampoco el autor siciliano consigue desvelar la realidad de lo ocurrido y su indagación termina con un aparente fracaso. Sin embargo, lejos de sentirse por ello decepcionado, el investigador cree que con su labor ha situado los hechos en su verdadera dimensión:

Puede que esos puntos oscuros que brotan de los documentos, de los recuerdos, parecían, en la inmediatez de los hechos, totalmente probables y explicables. Los hechos de la vida siempre se vuelven más complejos y oscuros, más ambiguos y equívocos, o sea, tal y como verdaderamente son, cuando se los escribe -o sea, cuando de 'actas relativas' pasan a ser, por así decirlo, 'actas absolutas' (SCIASCIA 2010: 61). 
Tras Atti relativi alla morte di Raymond Roussel, los demás racconti-inchiesta de Sciascia reincidirán en esta peculiar hermenéutica periodístico-literaria, que tiene en las operaciones de lectura, escritura y reescritura sus instrumentos heurísticos más penetrantes para la comprensión de la realidad. En concreto, el corpus sciasciano de racconti-inchiesta se compone de diez obras. Además de la ya citada, son las siguientes:

- La scomparsa di Majorana (La desaparición de Majorana, 1975²)

- I pugnalatori (Los apuñaladores, 1976)

- L'affaire Moro (El caso Moro, 1978)

- Dalle parte degli infedeli (De parte de los infieles, 1979)

- Il teatro della memoria (El teatro de la memoria, 1981)

- La sentenza memorabile (La sentencia memorable, 1982)

- Cronachette (Pequeñas crónicas, 1985)

- La strega e il capitano (La bruja y el capitán, 1986)

$-1912+1(1912+1,1987)$.

Los acontecimientos investigados en cada uno de estos reportajes novelados se enmarcan en épocas históricas diferentes. Algunos, como La sentenza memorabile, La strega e il capitano y Cronachette, se remontan a la época de la Inquisición o, tal es el caso de I pugnalatori, al periodo decimonónico de la Unificación Italiana. La mayoría, no obstante, se desarrollan en el siglo XX: bien sea en sus primeros años $(1912+1)$, bien durante el régimen fascista de Mussolini -Atti relativi alla morte di Raymond Roussel, La scomparsa di Majorana, Il teatro della memoria- o bajo el gobierno de la Democracia Cristiana (como L'affaire Moro y Dalle parte degli infedeli). En todos ellos, lo que Sciascia desarrolla es "la investigación de episodios oscuros, corrupciones e iniquidades cometidas por los diversos poderes que en el mundo son, bien sean fácticos, como la mafia y los grupos terroristas, bien institucionales, como la Iglesia y el Estado" (CHILlón, 1999: 326). Son “crónicas-denuncia' que instigan "a la desconfianza razonada ante los discursos oficiales de los poderes organizados" (REIJA 2010: 93) y que de algún modo también sirven, aunque sea alegóricamente, para comprender la siempre tensa y turbia actualidad política italiana de las décadas 1970 y 1980, desde las que SCIASCIA escribe.

Examinaremos a continuación con un poco más de detalle las características temáticas, estilísticas y compositivas propias de los racconti-inchiesta sciascianos, haciendo especial referencia a La scomparsa di Majorana, I pugnalatori y L'affaire Moro, pues nos parecen sus investigaciones más representativas y logradas.

En La scomparsa di Majorana, que apareció por entregas en las páginas del diario La Stampa entre el 31 de agosto y el 7 de septiembre de 1975, SCIASCIA indaga en la la misteriosa desaparición en marzo de 1938 del joven físico Ettore Majorana, que

${ }^{1}$ En el elenco de obras de SCIASCIA añadimos entre paréntesis la traducción española del título y el año de la edición original. Hemos empleado, siempre que ha sido posible, la versión española de cada obra, como figura en la bibliografía final. 
había comunicado a un amigo su intención de suicidarse y cuyo rastro se perdió poco después en una travesía en barco entre Nápoles y Palermo. Majorana trabajaba en el grupo de científicos que bajo la dirección de Enrico Fermi descubrió la escisión del átomo, hallazgo que precedió a la fabricación de la bomba atómica. La hipótesis que defiende Sciascia en su racconto-inchiesta es que, dado su carácter de genio como atestiguan quienes le conocieron, Majorana pudo intuir con bastante antelación que el fruto de sus investigaciones podría ser utilizado como un arma mortífera y, rechazando tal posibilidad por inmoral, decidió desaparecer, pero haciendo creer que se había suicidado. Esta hipótesis se sustenta sobre una sólida labor de investigación en la que Sciascia, enmarcando los hechos en su contexto político-social, cultural y científico, maneja todas las fuentes primarias disponibles (epistolario del protagonista de los hechos, documentos policiales sobre la investigación del caso, testimonios de sus compañeros de laboratorio, ensayos científicos, crónicas periodísticas de la época, etc.). Alberga la seguridad de que estos documentos exigen ser leídos con perspicacia $y$, en ocasiones, incluso reescritos para extraer de ellos todo aquello que pueda aproximar a la verdad sobre la vida y desaparición de Ettore Majorana.

Sciascia quiere "encontrar" al científico desaparecido y es consciente de que sólo podría hacerlo tomando como punto de partida esa escasa documentación (SCIASCIA, 1994: 13). Intenta hallarlo por medio de la escritura, "escribiendo estas páginas sobre su vida" (SCIASCIA, 1994: 56). Para escribir sobre su vida antes debe leerla y revivirla. Por eso, una exégesis correcta de los documentos requiere primero ponerlos en orden, "buscando en ellos un hilo conductor y una aclaración" (SCIASCIA, 1979: 87), detectando también las lagunas e imprecisiones de su contenido. Así lo explicaba en Cronachette:

Los pequeños acontecimientos del pasado, esos que los cronistas relatan con imprecisión o reticencia y que los historiadores pasan por alto, a veces abren en mi labor cotidiana como un paréntesis, algo muy parecido a las vacaciones (...) La imprecisión o la reticencia con que se relatan los hechos es, naturalmente, la condición indispensable para que se desencadene el divertimento. Después viene el gusto por la indagación, por hacer encajar los datos o ponerlos en contradicción, hacer hipótesis, conseguir una verdad o establecer un misterio allí donde la falta de verdad no era un misterio o su presencia no era misteriosa (SCIASCIA, 1986: 65).

En último término, el éxito de la exégesis está condicionado por el grado de identificación que llegue a alcanzar el intérprete con el autor de los textos que ha de interpretar. En el caso de La scomparsa di Majorana, al igual que en L'affaire Moro, esto reviste una importancia aún mayor porque uno y otro están construidos en torno al drama vivido por una determinada persona (Ettore Majorana y Aldo Moro, respectivamente), del que dan constancia las últimas cartas que ambos escribieron ${ }^{2}$.

\footnotetext{
${ }^{2}$ En el caso de Aldo Moro, conviene recordar que era el presidente de la Democracia Cristiana italiana y que fue secuestrado por las Brigadas Rojas el 16 marzo de 1978, cuando se dirigía a la presentación del nuevo gobierno de Giulio Andreotti, el primero que contaba con el apoyo del Partido Comunista Italiano (PCI). Los partidos se alinearon en dos grandes bloques con opiniones contrapuestas sobre cómo reaccionar ante el secuestro de Moro: por un lado, los democristianos, comunistas y republicanos defendían la "línea de la firmeza"; por
} 
En coherencia con su hermenéutica esencialmente literaria, Sciascia busca esa identificación con uno y otro según el modelo de un personaje de ficción, en concreto "el caballero Charles Auguste Dupin, el investigador de Poe, [que] consideraba precepto de toda investigación la capacidad de identificarse, de sumirse en el otro" (SCIASCIA, 1999: 42). Para alcanzarla no basta con una observación atenta de los indicios, ni con un análisis cuidadoso de los documentos y testimonios. Debe añadirse a la deducción lógica una inteligencia que simplifique las cosas sin caer en el reduccionismo, que las comprenda en su sencillez; de modo intuitivo y poético (BACCHERETI, 1999: 143).

Pero, más aún, lo que revela desde el punto de vista hermenéutico aquel comentario del narrador de La scomparsa di Majorana es lo que explicado Gaetano CoMPAGNINO:

"en el momento en que el lector cambia de lugar el centro de gravedad del texto, el propio texto se encuentra dislocado en una dimensión (de verdad) nueva y diversa [...] Dado que leer es "producción de sentido", leer equivale a escribir el otro texto: no un texto distinto, sino aquel que, inscrito en el primero (objeto de la lectura), la lectura -la relectura- "produce", saca fuera -a la "superficie"- escribiéndolo/reescribiéndolo como era, $\mathrm{y}$, por eso mismo, también diferente (COMPAGNINO, 1994: 125).

SCIASCIA toma como modelo de esta labor de reescritura a "Pierre Menard, autor del Quijote", que define en L'affaire Moro como "uno de los cuentos más extraordinarios que Borges haya escrito" (SCIASCIA, 1999: 23). El cuento narra la historia de ese ficticio autor francés, que escribió en el siglo XIX los capítulos noveno y trigésimo octavo de la primera parte del Quijote, y un fragmento del capítulo veintidós; iguales, en cada palabra y cada coma, a los escritos originalmente por Cervantes y, sin embargo (sostiene el narrador), sin ser una copia: "El texto de Cervantes y el de Menard son verbalmente idénticos, pero el segundo es casi infinitamente más rico" (BORGES, 1985: 56). Así pues, por medio de la lectura y de la reescritura, un texto, aun siendo el mismo en su literalidad, puede adquirir diferentes significados dentro de un nuevo contexto.

Como reconocía SCIASCIA, todo ese proceso vinculado a la lectura, escritura y reescritura es determinante en la conformación de su universo poético: "Ya no es posible escribir: se reescribe. Y en este obrar-más o menos conscientemente- hay desde un reescribir que atañe al escribir (Borges) hasta un torpe y a veces indigno reescribir. Por así decirlo, yo he hecho del reescribir mi poética: un reescribir consciente, abierto, que no es torpe y en absoluto innoble" (SCIASCIA, 1987: XVI). No es innoble

otro, el Partido Socialista y el Partido Radical abogaban por el diálogo y la "línea de la negociación" con los terroristas de extrema izquierda para intentar salvar la vida del líder democristiano. Se impuso aquella opción y el cadáver de apareció en el maletero de un coche en una calle romana el 9 de mayo, después de 55 días de cautiverio. Como concreción simbólica del compromesso storico del que él era principal valedor (la convergencia, beneficiosa en términos de rédito político, de dos partidos antitéticos ideológicamente como eran la DC y el PCI), las Brigadas Rojas abandonaron el vehículo en una calle situada a medio camino entre las sedes romanas de ambos partidos. 
porque esta labor periodístico-literaria se arraiga en el convencimiento de que la escritura tiene una capacidad performativa, de que "todo está vinculado al problema de la justicia, en el que se entremezclan los problemas de la libertad, de la dignidad humana, del respeto entre los hombres. Es un problema que se asoma a la escritura, que en la escritura encuentra redención o condena" (SCIASCIA, 1987: XXI).

Por eso, en La scomparsa di Majorana afirma que, aunque ya fueron publicadas y son de dominio público, conviene releer con detenimiento las últimas cartas escritas por Ettore Majorana antes de desaparecer. Y de la misma manera sucede con los demás documentos que el escritor integra en todos sus racconti-inchiesta porque, en definitiva, como afirma Claude AMBROISE:

"Sciascia cree en la posibilidad de alcanzar, a través de las trazas escritas dejadas en los archivos, la verdad de los hechos pasados. Por lo menos, es posible descubrir que la verdad ha sido escondida, que ha existido, que la impostura de los papeles encierra una verdad. Las cosas pueden no haber ocurrido como el redactor del documento intentaría hacernos creer pero, al menos como ausencia, la verdad es intuible. La verdad está en la relación entre el texto y quien lo ha escrito. De ahí también la importancia decisiva de la reescritura, del trabajo propiamente literario operado por Sciascia sobre el material encontrado" (AMBROISE,1987: XLIV).

Esto se advierte también en I pugnalatori que, un año después de La scomparsa di Majorana, fue publicado por entregas en el diario La Stampa. El crítico literario del periódico turinés propuso el tema a Sciascia, dándole un libro que reconstruía los hechos que tuvieron lugar en Palermo la noche del 1 de octubre de 1862, cuando trece personas -a la misma hora y en varios puntos de la ciudad casi equidistantes- fueron gravemente heridas por arma blanca. El fiscal que conducía la investigación, Guido Giacosa, descubrió que tras las agresiones existía un complot político urdido con el fin de aterrorizar a la población, para que sintiera la falta de orden y añorase el régimen borbónico, sustituido poco antes por la dinastía de los Saboya para la incipiente Unificación italiana. La conspiración estaba dirigida por el príncipe de Sant'Elia, un noble palermitano que, gracias a su condición de senador y a la cobertura política que recibía desde Roma, logró obstaculizar la labor del fiscal, que no encontró apoyo dentro de las instituciones en su voluntad de aplicar rectamente la justicia.

Sciascia investigó en archivos de Palermo y Roma, se puso en contacto con la bisnieta de Giacosa y, con la abundante información recopilada, escribió un raccontoinchiesta que, como apunta Joaquín AgUiRre (2008: web), "posee una vertiente claramente hermenéutica, ya que lo que nos muestra es un proceso de lectura por parte del "autor" de cuyas conclusiones que hace partícipes a sus lectores. El texto pasa a ser el resultado una lectura manifiesta".

Como señalaba SCIASCIA (2008: 125) en la nota final de I pugnalatori, su reportaje novelado buscaba ser "un relato que resulte claro al mayor número de personas, y que interese. Que interese, quiero decir, en relación con lo que ocurre hoy". No le movía, por tanto, una intención historicista, sino la voluntad de presentar un episodio que mostraba que la clase política italiana apenas había cambiado desde los albores de la Unificación y que, todo aquello que él venía denunciando en sus columnas en la prensa 
y, sobre todo, en sus más recientes novelas policíacas, no era un fenómeno nuevo, sino que hundía sus raíces en el pasado. Desde ese punto de vista, la conspiración dirigida por el príncipe de Sant'Elia en 1862 aparecía como el antecedente remoto de la "estrategia de la tensión" en que estaba sumida Italia desde la masacre de Piazza Fontana en $1969^{3}$. También las tramas de preservación del poder por medio de la violencia y la mentira que ya operaban en el Palermo decimonónico -reveladas por Sciascia en I pugnalatori- se habían perpetuado hasta ese momento, como quedaba constancia en sus novelas Il contesto (1971) o Todo modo (1974); de igual modo que la actuación honrada y acorde a la ley del magistrado Giacosa y desautorizada por sus superiores era idéntica a la experiencia sufrida por algunos personajes salidos de su pluma, como el capitán Bellodi (Il giorno della civetta, 1961) o el comisario Rogas (Il contesto).

La vida institucional y política del país transalpino, a menudo oscura y turbulenta, se sitúa, por tanto, en el centro de la actividad literaria y periodística de Sciascia. Una dinámica que llegará a su culmen en 1978, con el secuestro y asesinato del entonces presidente de la Democracia Cristiana, Aldo Moro ${ }^{4}$. El escritor siguió con gran atención el desarrollo de los hechos, pero evitó pronunciarse sobre el asunto hasta poder enjuiciarlo con suficiente perspectiva. Pocas semanas después de que apareciera el cadáver de Moro, sin más ayuda material que "una marejada de recortes de periódicos y con el diccionario de Tommaseo bien sólido en el centro, como un rompeolas" (SCIASCIA, 1999: 115), analizó con rigor filológico las cartas que el líder democristiano había enviado durante su secuestro y los comunicados de las Brigadas Rojas, llegando a la conclusión de que aquel podría haberse salvado si la investigación policial hubiera sido más eficaz y si se hubiera intentado una negociación con los terroristas que, aunque negada por "razón de Estado", sí se había llevado a cabo en otras ocasiones. La mayoría de los políticos y periodistas no otorgaba valor a aquellas cartas, pues atribuía su contenido a la presión de los captores o a la locura en la que había desembocado Moro. Sin embargo, a Sciascia ese dramático intento de diálogo de Moro con sus compañeros democristianos para salvar su vida le inspiraba piedad. No obstante, en su opinión era inútil la petición del político para que éstos negociasen su liberación, pues su secuestro en realidad favorecía el clima de concordia en que se había aprobado el gobierno de Giulio Andreotti y en el que contaban por primera vez con la colaboración del Partido Comunista. Se verificaba así, por decirlo con Elías CANETTI, "la frase más monstruosa de todas: alguien murió "en el momento justo"'s.

${ }^{3}$ Como es sabido, la expresión "estrategia de la tensión" hace referencia a los atentados terroristas organizados por grupos de extrema derecha con la colaboración de los servicios secretos del Estado italiano, con el objetivo de crear una situación de alarma y terror que justificara la instauración de un estado policial, y atribuyendo la responsabilidad de los atentados a la extrema izquierda para deslegitimar al PCI (GINSBORG, 2003: 333-335).

${ }^{4}$ Cfr. supra nota 2.

${ }^{5}$ La frase pertenece al libro La provincia del hombre, que recoge los apuntes de CANETTI entre 1942 y 1972, y es el epígrafe elegido por Sciascia para L'affaire Moro (SCIASCIA, 1999: 7). 
Como era de esperar, L'affaire Moro, que Sciascia presentaba como "la pura y dura búsqueda de la pura y dura verdad", suscitó una fuerte controversia en la esfera pública italiana (VECELLIO, 2002). La obra, en cualquier caso, es un ejemplo de rigor en la investigación de los hechos y, al mismo tiempo, de honestidad intelectual, por cuanto que el autor no esconde, en palabras de ReIJA (2010: 96), que "pese a la indagación y la formulación de hipótesis sobre causas y móviles, no se puede llegar a ninguna certeza, ninguna verdad indiscutible (sólo a verdades plausibles)". Lo cual es un rasgo propiamente periodístico como bien lo explica Tomás Eloy MARTínEZ:

"De todas las vocaciones del hombre, el periodismo es aquélla en la que hay menos lugar para las verdades absolutas. La llama sagrada del periodismo es la duda, la verificación de los datos, la interrogación constante. Allí donde los documentos parecen instalar una certeza, el periodismo instala siempre una pregunta" (MARTíNEZ, 2006: 235).

Más aún, cabe sostener que desde Atti relativi alla morte di Raymond Roussel hasta 1912+1 Sciascia, en mayor o menor medida, tiende siempre "a dejar abiertas las interpretaciones y crear un cierto hermetismo eterno" (VILA-MATAS, 2010: 39). En la misma dirección apunta Carlo Alberto MADRIGNANI sobre el modo en que el escritor siciliano practica el género del racconto-inchiesta:

"en todos estos encuentros, la historia es siempre una historia de hechos minúsculos, de acontecimientos casi microscópicos; se tiene la impresión de que el escritor quiera contraponer "su" historia de advenimientos larvales, de encuentros secretos, de oscuras epifanías a la historia de letras claras que todos conocemos, o que creemos conocer [...] La ayuda de la documentación más extensa no basta para llegar al fondo del conocimiento de los hechos y de los hombres, permanece un elemento de misterio, una última inaccesible oscuridad, que el escritor-históricopsicólogo tantea, roza, intuye, sin llegar a eliminarla" (MADRIGNANI, 1977: 336).

Junto con esa tensión continua entre verdad y misterio, en la escritura sciasciana se manifiesta el intento de hallar un sentido a la realidad, buscando un conocimiento que va más allá de la simple veracidad documental. La de Sciascia es la indagación de una verdad esencial, dirigida a la comprensión del comportamiento de los individuos en la historia (Chillón, 1999: 327).

Esa búsqueda de lo esencial encuentra reflejo en el plano estilístico, como indica Federico CAMPBELL, en "ese 'estilo notarial' que parece eludir el regocijo, el 'gusto lúdico' por la palabra, y no querer hacer 'literatura' de las cosas. Al contrario: desliteraturizarlas, desideologizarlas" (1989: 16). De ahí su tendencia a la sobriedad expositiva y a la concisión, como explica en una anotación final del racconto-inchiesta titulado $1912+1$ :

Como siempre -y cada vez más conforme avanzan (esto es, retroceden) los añoshe buscado la concisión. Se trata de una vieja aspiración que tengo, como codificada, en la transcripción ahora ya in pectore de la parte aquélla de las voces 'sucinto, preciso, conciso' que en el Diccionario de sinónimos del viejo e incomparable Tommasseo atañe de forma más expresa al arte de escribir (y creo justo y oportuno deleitar aquí con ello al lector): "No puede ser escritor conciso quien no es preciso, porque al no tener un conocimiento exacto de las cosas, errará en todo momento en la propiedad de 
las voces, de la que se deriva la brevedad y claridad, ese bello estilo al que nada es posible quitar ni poner sin desmedro de su mérito". He tratado, pues, de buscar la concisión. Que lo haya logrado es otro asunto, que ya no me concierne" (SCIASCIA, 1989a: 118-119).

Esta voluntad estilística de concisión y claridad le lleva a elogiar la superficialidad, entendida no como lugar común y ausencia de rigor, sino como consecuencia de un fenómeno cognoscitivo por medio del cual la razón, desde la serenidad y libertad interior, lleva hasta la superficie la hondura de las cosas, porque "no hay lugar profundo que la inteligencia no pueda volver superficial" (SCIASCIA, 1990a: 211).

Este proceso, tan nuclear en el desarrollo de todos sus racconti-inchiesta, tiene como meta final la vivencia y transmisión de la verdad; resultado de un recorrido hermenéutico por el cual Sciascia intenta descifrar la realidad leyéndola y escribiéndola, extrayendo lo sencillo de lo complejo. Es de este modo como concibe su tarea de escritor:

El escritor desvela la verdad descifrando la realidad y elevándola a la superficie, en cierto sentido simplificándola, también haciéndola más oscura, como la realidad a menudo es [...] Existe, no obstante, una diferencia entre esta oscuridad y la de la ignorancia: ya no se trata de la oscuridad de lo inexpresado, de lo informe; sino, al contrario, de lo expresado y de lo formulado (SCIASCIA, 1979: 87).

Su peculiar modalidad de investigación periodístico-literaria rescata a la realidad de la complejidad y de la profundidad (la lleva con la inteligencia a la superficie), pero no necesariamente de la oscuridad. Restituye el verdadero sentido de los hechos -aunque siga siendo una verdad misteriosa- porque los libera de la retórica y la mistificación que provienen del poder y del Estado, vistos por Sciascia como una máquina productora de mentira (SCIASCIA, 1982: 155). A este respecto, el escritor siciliano piensa que la historiografía tampoco está libre de dicha falsedad, pues puede ser empleada como instrumento de justificación ideológica. La escritura, ya sea totalmente ficcional o híbrida entre lo literario y lo periodístico, es necesaria para la comprensión del pasado y por eso recurre a ella, también como lector:

Descubro en la literatura aquello que no logro descubrir en los analistas más elucubrantes, esos que querrían ofrecer explicaciones y soluciones a todos los problemas. Sí, la Historia miente y sus mentiras envuelven de un mismo polvo todas las teorías que nacen de la Historia [...] Se descubre una verdad histórica, no ya en un texto de historia, sino en las páginas de una novela; no en un docto análisis, sino gracias a una descripción novelada (SCIASCIA, 1979: 82).

Por todo lo anterior, Sciascia llega a la convicción de que la escritura es el espacio donde la verdad puede alcanzar su plenitud, abandonando así una concepción de aquella como engaño y falsificación:

"En mi casa siempre se ha respirado un infinito respeto por las cosas de la escritura, un respeto y un miedo típicos del mundo campesino. Para el campesino, ¿la escritura no es quizá engaño, impostura y falsificación? [...] De la scrittura-inganno, como era para el campesino y como era para mí mismo, he llegado a la scrittura-verità y me he convencido de que, si la verdad necesariamente ofrece muchas caras, la única forma posible de verdad es aquella del arte" (SCIASCIA, 1979: 87). 
Unido a lo anterior, y superando la naturaleza trágica de la "materia prima" con que elabora sus investigaciones periodístico-literarias, Sciascia piensa que su oficio es una potenciación del placer de vivir; que por "muy amargas, dolorosas y angustiosas que sean las cosas sobre las que uno escribe, el escribirlas es ya siempre un motivo de alegría, un "estado de gracia"' (SCIASCIA, 1989b: 108). Y en la misma medida en que el autor disfrute con la escritura, así será para el lector su recepción (SCIASCIA, 2007: 294).

\section{Conclusiones}

El conjunto de diez racconti-inchiesta escritos por Leonardo Sciascia constituye un fenómeno interesante de mixtura del discurso periodístico con el discurso literario. Los relatos de investigación de Sciascia son una modalidad de escritura facticia, en el sentido dado por CHILLÓN (2006), porque -a diferencia de la ficticia (que tiene total libertad para refigurar "lo real", impulsada por una imaginación sin fines veridicentes)- aquella lleva a cabo dicha refiguración de la realidad desde el compromiso ético de referirlo tal cual es, del modo más fehaciente posible. En obras como I pugnalatori, L'affaire Moro o Il teatro della memoria Sciascia articula observaciones, conjeturas, silogismos con base en los documentos recabados en torno a unos determinados hechos, para ir trenzando suposiciones probables por medio de tramas narrativas que permiten dar orden y sentido al acontecimiento sometido a indagación (CHILLÓN 2006: 23).

Presenta, por tanto, una prosa no ficticia que es al mismo tiempo periodismo y literatura porque, como ha explicado LóPEZ PAN (2010) siguiendo a GeNETTE (1991 y 2003), "una obra puede ser reconocida como constitutivamente literaria y simultáneamente apreciada como obra de dicción" " (LóPEZ PAN, 2010: 109).

Desde el punto de vista metodológico, la práctica sciasciana del racconto-inchiesta se sustenta sobre "una compleja y fértil hermenéutica lingüística y filológica que a la vez se contrasta continuamente con la realidad fáctica, en una continua denuncia del documento histórico y el discurso político como máscaras y laberintos de la verdad" (REIJA, 2010: 90). Frente a las mentiras, por tanto, de la historiografía oficial y de los poderes institucionales, y animado por un sano escepticismo, Sciascia contrapone las armas de la perspicacia y de la palabra (leída, escrita, reescrita), con la voluntad de restituir la verdad de los hechos investigados.

\section{Referencias bibliográficas}

AGUIRRE ROMERO, Joaquín Ma (2008): "Discurso y construcción histórica", Recorte. Revista de Linguagem, Cultura e Discurso, Año 5, $\mathrm{n}^{\circ}$ 8, enero-junio. $<$ http://www.unincor.br/recorte/artigos/edicao8/8_artigo_joaquim.html $>$ [Fecha de consulta: 20/02/2011].

${ }^{6}$ La obra de dicción es la que se impone esencialmente por su características formales (y no
por el carácter imaginario de sus objetos, que es lo propio de la obra de ficción). 
AMBROISE, Claude (1987): "Verità e scrittura", en SCIASCIA, Leonardo, Opere 1956-1971, Milano, Bompiani, pp. XXV-XLVII.

AMBROISE, Claude (1995): “La letteratura come strumento di verità?", en LANDI, Stefano, (ed.): Leonardo Sciascia. Cinema e letteratura. Pordenone, Cinemazero, pp. 11-21.

AURELL, Jaume (2005): La escritura de la memoria. De los positivismos a los postmodernismos. Valencia, Publicacions de la Universitat de València.

BACCHERETI, Elisabetta (1999): "Il razionali mistero: il poliziesco di Sciascia tra Poe, Gadda e Pirandello", en CINCOTTA, R. (ed.): Da un paese indicibile, Quaderni Leonardo Sciascia, $n^{\circ}$ 4. Milano, La Vita Felice, pp. 139-178

BORGES, Jorge Luis (1985): Ficciones. Barcelona, Planeta-Agostini.

CAMPBELL, Federico (1989): La memoria de Sciascia. México, Fondo de Cultura Económica.

CANETTI, Elías (1982): La provincia del hombre. Carnet de notas 1942-1972. Madrid, Taurus.

CASALS CARRO, María Jesús (2005): Periodismo y sentido de la realidad. Teoría y análisis de la narrativa periodística. Madrid, Fragua.

CHILLÓN, Lluis Albert (1999): Literatura y Periodismo: una tradición de relaciones promiscuas. Bellaterra, Universitat Autonoma de Barcelona.

CHILLÓN, Lluis Albert (2006): "Las escrituras facticias y su influjo en el periodismo moderno", en Trípodos, n 19, Barcelona, pp. 9-23.

COMPAGNINO, Gaetano (1994): Leonardo Sciascia nella terra dei letterati. Acireale, Bonanno Editore.

GENETTE, Gérard (1991): Ficción y Dicción. Barcelona, Lumen.

GENETTE, Gérard (2003): "Fiction ou diction", Poétique, no 134, pp. 131-139.

GINSBORG, Paul (2003): A History of Contemporany Italy: society and politics, 1943-1988. New York, Palgrave Macmillan.

LÓPEZ PAN, Fernando (2010): "Periodismo literario: entre la literatura constitutiva y la condicional", en Ámbitos: Revista Internacional de Comunicación, $\mathrm{n}^{\circ} 19$, Sevilla, pp. 97-116.

MADRIGNANI, Carlo Alberto (1977): “I pugnalatori”, en MOTTA, Antonio (1985) (ed.): Leonardo Sciascia. La verità, l'aspra verità. Manduria, Lacaita, pp. 335-340.

MANZONI, Alessandro (2008): Historia de la columna infame. Con una nota de Leonardo Sciascia. Barcelona, Barataria.

MARTÍNEZ, TOMÁS ELOY (2006): La otra realidad. Antología. Buenos Aires, Fondo de Cultura Económica.

NIGRO, Salvatore Silvano (ed., 2003): Leonardo Sciascia scrittore editore. Palermo, Sellerio. 
REIJA, JULIO (2010): “A modo de contexto", en SCIASCIA, Leonardo, Actas relativas a la muerte de Raymond Roussel. Madrid, Gallo Nero, pp. 81-109.

SCIASCIA, Leonardo (1979): La Sicilia come metafora, intervista di Marcelle Padovani. Milano, Mondadori.

SCIASCIA, Leonardo (1982): La Palma va a nord. Milano, Grammalibri.

SCIASCIA, Leonardo (1986): Mata Hari en Palermo. Barcelona, Montesinos.

SCIASCIA, Leonardo (1987): "14 domande a Leonardo Sciascia", conversazione con C. Ambroise, en SCIASCIA, L.: Opere 1956-1971. Milano, Bompiani, pp. XVXVIII.

SCIASCIA, Leonardo (1989a): 1912+1. Barcelona, Tusquets.

SCIASCIA, Leonardo (1989b): La bruja y el capitán. Barcelona, Tusquets.

SCIASCIA, Leonardo (1990a): Crucigrama. México, Fondo de Cultura Económica.

SCIASCIA, Leonardo (1990b): La sentencia memorable. Madrid, Mondadori.

SCIASCIA, Leonardo (1991): Opere (1984-1989). Milano, Bompiani.

SCIASCIA, Leonardo (1993): De parte de los infieles. Autos relativos a la muerte de Raymond Roussel. Madrid, Mondadori.

SCIASCIA, Leonardo (1994): La desaparición de Majorana. Barcelona, Editorial Juventud.

SCIASCIA, Leonardo (1999): El caso Aldo Moro. Barcelona, Destino.

SCIASCIA, Leonardo (2007): Negro sobre negro. Barcelona, Global Rythm Press.

SCIASCIA, Leonardo (2008): Los apuñaladores. Barcelona, Tusquets.

SCIASCIA, Leonardo (2009): El teatro de la memoria. Barcelona, Tusquets.

SERRANO, Javier (2011): "Leonardo Sciascia, escritor en prensa: sus colaboraciones con diarios italianos (1955-1989)", Comunicación y Sociedad, vol. XXIV, n 1 , 2011, pp. 167-187.

TANI, Stefano (1990): Il romanzo di ritorno. Milano, Mursia.

TRAINA, Giuseppe (1999): Leonardo Sciascia. Milano, Bruno Mondadori.

VECELLIO, Valter (ed., 2002): L'uomo solo. L'affaire Moro di Leonardo Sciascia. Quaderni Leonardo Sciascia, $n^{\circ} 7$. Milano, La Vita Felice.

VILA-MATAS, Enrique (2010): “Una versión no oficial”, en El Pais, 23 de noviembre, p. 39. 